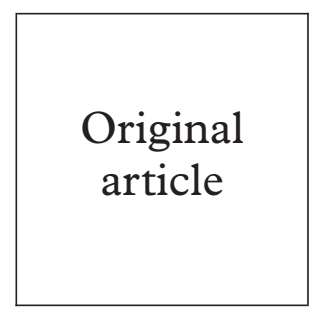

Original article

${ }^{\star}$ Members listed at end of paper

Correspondence to: Dr Chris Carne, Clinic 1A, Box 38, Addenbrooke's NHS Trust Hospital, Hills Road,

Cambridge CB2 2QQ christopher.carne

(a) msexc.addenbrookes .anglox.nhs.uk

Accepted for publication 7 June 2000

\title{
Screening for HIV infection in genitourinary medicine clinics: a lost opportunity?
}

\author{
British Co-operative Clinical Group $\star$
}

Objectives: To examine the policy and practice of HIV testing in genitourinary medicine clinics in the United Kingdom.

Design: All 176 consultants in charge of genitourinary medicine clinics in the United Kingdom were sent a policy and practice questionnaire. A self selected group of 53 clinics conducted a retrospective case note survey of the first 100 patients seen in each clinic in 1998.

Setting: Genitourinary medicine clinics in the United Kingdom.

Subjects: Consultants in charge of, and case notes of patients attending, genitourinary medicine clinics.

Interventions: None

Main outcome measures: Number of patients tested for HIV.

Results: Consultants' assessments of their rate of HIV testing often exceeded the actual rates of testing in the clinic as a whole. The majority of patients deemed to be at high risk requested an HIV test. The exception were heterosexuals who had lived in sub-Saharan Africa. Among attenders at high risk of HIV who did not request a test, 57/196 (29\%) were not offered one by clinic staff. Two fifths $(51 / 130)$ of consultants felt the proportion of patients tested in their clinic was too low. The commonest reason given for this was a lack of time, especially that of health advisers.

Conclusions: A substantial minority of people with HIV infection attending genitourinary medicine clinics fail to have their infection diagnosed. Two major reasons were identified. Firstly, a test was not always offered to those at high risk of HIV. Secondly, a lack of resources, mainly staff, which prevents some clinics from increasing their level of testing.

(Sex Transm Inf 2000;76:307-310)

Keywords: screening; HIV; genitourinary medicine clinics

\section{Introduction}

Most infections with human immunodeficiency virus (HIV) in England and Wales are diagnosed in genitourinary medicine clinics. Unlinked anonymous HIV testing, however, has shown that a substantial minority of infected people attending these clinics fail to have their HIV infection diagnosed. The proportions of infected people in different risk categories who were undiagnosed were 39\% (174 of 450) for homosexual and bisexual men, $45 \%$ (58 of 129) for heterosexual men, $50 \%$ (72 of 144) for heterosexual women, and 12\% (three of 25) for those who admitted having injected drugs. ${ }^{1}$

The advantages of diagnosing HIV infection early are twofold. Firstly, recent advances in antiretroviral drug therapy and in monitoring HIV levels in blood have produced substantial reductions in mortality from AIDS. ${ }^{2}$ The expert consensus is that these drugs are best begun before the onset of severe immunosuppression. ${ }^{3}$ Secondly, HIV infected people who know their diagnosis have been shown to avoid unsafe sex to a greater extent than those who are undiagnosed. ${ }^{4}$

The failure to diagnose HIV infection is an important public health issue. This may occur either through patient choice or as a result of other factors. To determine the reasons why patients with HIV remained undiagnosed, we surveyed consultants in genitourinary medi- cine clinics in the United Kingdom and conducted a retrospective audit.

\section{Methods}

All 176 consultants in charge of genitourinary medicine clinics in the United Kingdom were surveyed in October 1998. Those consultants in charge of two or more clinics were invited to make only one return. A self completed questionnaire inquired into the consultant's own clinical practice, the policy and practice in their clinic, and their opinions regarding HIV testing. A structured retrospective case note survey of the first 100 patients seen in 1998 (excluding those returning for follow up) was optional. This examined whether the patient had had a previous HIV test, whether they requested or were offered a test, whether an HIV test was performed and, if so, its result. The patient's risk factors for HIV were also recorded and if a discussion with the health adviser took place pretest and/or post-test.

\section{Results}

The policy and practice questionnaire was completed by $133(76 \%)$ consultants in charge of genitourinary medicine clinics in the United Kingdom. One gave no indication of where it was sent from, and was excluded from the data analysis.

The consultant in charge estimated the percentage of patients in different risk categories to whom he or she offered an HIV test. The 
Table 1 Distribution of 130 GUM clinics according to the percentage of patients routinely offered an HIV test, estimated by the physician in charge

\begin{tabular}{|c|c|c|c|c|c|}
\hline \multirow[b]{2}{*}{ Exposure category } & \multicolumn{5}{|c|}{ Number of clinics with the following estimated percentages of patients offered HIV test } \\
\hline & $0 \%$ & $1-25 \%$ & $26-50 \%$ & $51-75 \%$ & $76-100 \%$ \\
\hline \multicolumn{6}{|l|}{ High risk } \\
\hline Sexually active homosexual/bisexual man & 2 & 4 & - & 5 & 119 \\
\hline Sexually active heterosexual from the UK, with a "high risk" contact & 3 & 4 & 3 & 3 & 117 \\
\hline Heterosexual who has lived in sub-Saharan Africa & 5 & 2 & 2 & 3 & 113 \\
\hline Injecting drug users who have shared equipment & 3 & 4 & 1 & 3 & 119 \\
\hline Injecting drug users who deny sharing & 7 & 6 & 6 & 8 & 102 \\
\hline \multicolumn{6}{|l|}{ Low risk } \\
\hline Sexually active heterosexual from the UK, who denies "high risk" contact & 12 & 30 & 13 & 13 & 58 \\
\hline Heterosexual from the UK with acute STI $\dagger$ & 10 & 25 & 21 & 10 & 60 \\
\hline Heterosexual who has lived abroad (other than sub-Saharan Africa) & 7 & 21 & 22 & 10 & 63 \\
\hline
\end{tabular}

*Number of clinics in each row does not add to 130 because of incomplete answers.

†Syphilis/gonorrhoea/chlamydia/NSU/T.V/scabies/pediculosis pubis/anogenital herpes-first attack/anogenital warts-first attack/molluscum contagiosum/LGV/ donovanosis.

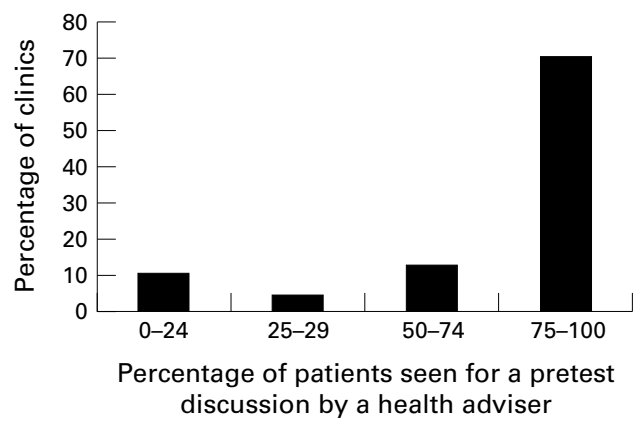

Figure 1 Distribution of the percentage of patients reported to have been seen by a health adviser for a pre-HIV test discussion at each clinic $(n=131)$. (0\% was reported by seven clinics; $100 \%$ was reported by 29 clinics.)

rates were, as expected, higher among patients known to be at high risk of HIV infection (table 1 ). The estimated rates of testing by the consultant proved to be higher than the true rate of testing in the clinics participating in the retrospective case note survey. Where the consultant had assessed his or her rate of testing as $100 \%$ for the various exposure categories, the clinic's actual rate of testing varied from $73 \%$ to $100 \%$ for the high risk exposures and $65 \%$ to $88 \%$ for the low risk exposures.

Ninety six per cent $(127 / 132)$ of responding clinics routinely offered patients information on the availability of the HIV test. This was more often given in a "passive" way-that is, leaflets which were available for patients to take $(100 / 132,76 \%)$, posters $(71 / 132,54 \%)$, or in one clinic by video. Only 48/132 (36\%) clinics actively gave leaflets to patients advertising the availability of the HIV test.

Table 2 Principal barriers to increasing the number of HIV tests

\begin{tabular}{ll}
\hline Barriers cited by consultants & $\begin{array}{l}\text { Number of } \\
\text { responses }\end{array}$ \\
\hline Patient dependent barriers & \\
Concerns about consequences of positive results: & 6 \\
Stigma & 5 \\
Fear/anxiety & 4 \\
Insurance issues & 2 \\
Inability to cope & 8 \\
Lack of awareness of risk & 3 \\
Unwillingness to wait or make further appointment & 6 \\
Other responses & \\
Clinic dependent barriers & 17 \\
Concerns about resources: & 6 \\
Lack of time (mostly that of health advisers) & 3 \\
Shortage of staff/cost of extra staff & 6 \\
Other responses & 3 \\
Concerns about offering the test: for example, clinic staff attitudes & \\
External factors: for example, General Medical Council policy on consent & 3 \\
\hline
\end{tabular}

The proportion (percentage) of pretest discussions that were performed by a health adviser is shown in figure 1 . Two thirds (87/131) of clinics had a written policy on HIV testing. Almost all (128/132) routinely checked an HIV positive result with a second blood sample.

A total of $20 \mathrm{HIV}$ positive patients diagnosed in the year up to 31 July 1998 had not been given their HIV test result by the time of the survey.

The results of the section on the consultants' opinions regarding HIV testing showed that 108/131 (82\%) agreed with current guidelines that pretest discussion is always necessary to ensure fully informed consent; 34/131 (26\%) favoured testing for HIV with assumed consent after it had been mentioned as one of a number of routine tests. The majority $(74 / 130,57 \%)$ of consultants felt that the proportion of attenders tested for HIV at their clinic was "about right." However, a substantial minority (51/130, 39\%) felt the proportion was "too low," while only $5 / 130(4 \%)$ believed it was "too high."

A total of 55 consultants gave examples of the principal barriers to increasing the number of tests (table 2).

Fifty three clinics completed the optional retrospective case note survey. Eleven of the participating clinics were from the former Thames regions. In all 4948 case note survey forms were returned. Two were excluded because the patients were attending for follow up of a diagnosis made in the previous calendar year. The median age of the male patients was 29 years (range $4-86$ years), and of females was 26 years (range $4-67$ years) (table 3 ). Twenty five per cent $(1236 / 4946)$ of patients requested an HIV test. The majority $(381 / 590,65 \%)$ of those at high risk of HIV requested a test (table 4). The exception was heterosexuals who had lived in sub-Saharan Africa (15/37, 41\%). The different approaches to promoting the test (for example, actively giving leaflets) were not associated with any statistically significant differences (using the $\chi^{2}$ test) in the rates of uptake of the HIV test.

The large majority of patients who requested an HIV test were actually tested (table 4). An extra 42 high risk patients who had not requested a test underwent HIV testing after being offered a test, as well as 209 of those classified as relatively low risk. Overall 407/590 (69\%) patients at high risk underwent HIV 
Table 3 Characteristics of patients in case note survey

\begin{tabular}{|c|c|c|c|c|}
\hline Exposure category & Male & Female & $\begin{array}{l}\text { Sex not } \\
\text { known }\end{array}$ & Total \\
\hline \multicolumn{5}{|l|}{ High risk } \\
\hline Sexually active homosexual/bisexual man & 250 & - & - & 250 \\
\hline Sexually active heterosexual from the UK, with a "high risk" contact & 114 & 131 & 4 & 249 \\
\hline Heterosexual who has lived in sub-Saharan Africa & 28 & 9 & 0 & 37 \\
\hline Injecting drug users who have shared equipment & 27 & 9 & 1 & 37 \\
\hline Injecting drug users who deny sharing & 13 & 4 & 0 & 17 \\
\hline Subtotal high risk & 432 & 153 & 5 & 590 \\
\hline \multicolumn{5}{|l|}{ Low risk } \\
\hline Sexually active heterosexual from the UK, who denies "high risk" contact & 1202 & 1451 & 44 & 2697 \\
\hline Heterosexual from the UK with acute STI* & 691 & 639 & 27 & 1357 \\
\hline Heterosexual who has lived abroad (other than sub-Saharan Africa) & 59 & 34 & 3 & 96 \\
\hline Subtotal low risk & 1952 & 2124 & 74 & 4150 \\
\hline Other ${ }^{\star}$ & 76 & 70 & 0 & 146 \\
\hline Unspecified & 29 & 29 & 2 & 60 \\
\hline Total & 2489 & 2376 & 81 & 4946 \\
\hline
\end{tabular}

*Other includes contacts of those with STIs, sexual assault, needlestick, and other exposures to blood, IVF screening, those not sexually active, non-acute STIs.

Note: 190 patients were reported with two exposures. They are included in this table, assigned to a primary exposure using the following algorithm: sex between men overrides all others, then IDU sharing, then sub-Saharan Africa. In UK, high risk partner overrides acute STI, which in turn overrides no high risk contact.

testing compared with $961 / 4150(23 \%)$ at low risk. A third (66/206) of patients in other and unspecified categories were also tested. Overall $5 / 1437(0.35 \%)$ were diagnosed as HIV infected, including four who had requested a test; these four patients comprised three homosexual men and a heterosexual African man. The other person who had not requested a test and was diagnosed as HIV infected was an African woman; she had seen a health adviser for pretest discussion.

Among the 1397 patients known to have undergone HIV testing, 1109 (79\%) were known to have seen a health adviser for a pretest discussion and $876(63 \%)$ saw one on the day they were given their result (including four of the five who tested positive).

Among attenders at high risk of HIV who did not request a test, it is known that 57/196 $(29 \%)$ were not offered one.

\section{Discussion}

Approximately $25000 \mathrm{HIV}$ infected adults were estimated to be living in the United Kingdom at the end of $1997 .^{1}$ This is equivalent to about one per 1000 aged 15-49. The prevalence in the United Kingdom is the sixth lowest among the 19 Western European countries. One of the reasons for this relatively low preva- lence is believed to be the availability of free and open access to genitourinary medicine clinics.

At the end of 1998, 31001 people had been diagnosed as HIV positive in the United Kingdom, ${ }^{5}$ of whom approximately 11000 had died. Therefore, approximately 20000 diagnosed HIV positive people were living at this time, some of whom were children. This implies that of the estimated $25000 \mathrm{HIV}$ positive adults living at this time, at least 5000 were unaware of their HIV status.

By the end of June 1999, 38675 people had been diagnosed HIV positive. ${ }^{6}$ The risk category of heterosexually acquired HIV infection is rising in absolute as well as relative terms. ${ }^{\circ}$

The survey found that almost all consultants in charge of clinics were inclined to offer HIV tests to patients who declared recognised high risk factors for infection. As many as half of the consultants also tended to offer tests to those at relatively low risk of HIV.

In the United States it has been reported that many people testing HIV positive at anonymous HIV testing sites fail to return to receive their results. ${ }^{7}$ This does not appear to be a common problem at genitourinary medicine clinics in the United Kingdom where, across the 132 responding clinics, only 20 patients

Table 4 Number of patients tested for HIV infection—survey of first 5000 patients seen in 1998 at 53 GUM clinics

\begin{tabular}{|c|c|c|c|c|c|c|}
\hline \multirow[b]{2}{*}{ Exposure category } & \multirow{2}{*}{$\begin{array}{l}\text { Total } \\
\text { surveyed } \\
(100 \%)\end{array}$} & \multicolumn{2}{|c|}{ HIV test requested } & \multicolumn{2}{|c|}{$\begin{array}{l}\text { HIV test offered but not } \\
\text { requested }\end{array}$} & \multirow[b]{2}{*}{$\begin{array}{l}\text { Number } \\
(\%) \text { testedf }\end{array}$} \\
\hline & & $\begin{array}{l}\text { Subtotal } \\
(100 \%)\end{array}$ & $\begin{array}{l}\text { Number } \\
\text { (\%) tested }\end{array}$ & $\begin{array}{l}\text { Subtotal } \\
(100 \%)\end{array}$ & $\begin{array}{l}\text { Number } \\
\text { (\%) tested }\end{array}$ & \\
\hline \multicolumn{7}{|l|}{ High risk } \\
\hline Sexually active homosexual/bisexual man & 250 & 161 & $156(97)$ & 51 & $19(37)$ & $180(72)$ \\
\hline Sexually active heterosexual from the UK, with a "high risk" contact & 249 & 164 & $154(94)$ & 61 & $15(25)$ & $170(68)$ \\
\hline Heterosexual who has lived in sub-Saharan Africa & 37 & 15 & $14(93)$ & 10 & $3(30)$ & $17(46)$ \\
\hline Injecting drug users who have shared equipment & 37 & 30 & $25(83)$ & 7 & $3(43)$ & $28(76)$ \\
\hline Injecting drug users who deny sharing & 17 & 11 & $10(91)$ & 3 & $2(67)$ & $12(71)$ \\
\hline Subtotal high risk & 590 & 381 & $359(94)$ & 132 & $42(32)$ & $401(69)$ \\
\hline \multicolumn{7}{|l|}{ Low risk } \\
\hline Sexually active heterosexual from the UK, who denies "high risk" contact & 2697 & 633 & $582(92)$ & 501 & $124(25)$ & $719(27)$ \\
\hline Heterosexual from the UK with acute STI ${ }^{\star}$ & 1357 & 109 & $91(83)$ & 376 & $77(20)$ & $187(14)$ \\
\hline Heterosexual who has lived abroad (other than sub-Saharan Africa) & 96 & 51 & $49(96)$ & 20 & $8(40)$ & $58(60)$ \\
\hline Subtotal low risk & 4150 & 793 & $722(91)$ & 897 & $209(23)$ & $964(23)$ \\
\hline Other* & 146 & 53 & $51(96)$ & 11 & $4(36)$ & $56(38)$ \\
\hline Unspecified & 60 & 9 & $9(100)$ & 35 & $1(3)$ & $10(17)$ \\
\hline Total & 4946 & 1236 & $1141(92)$ & 1075 & $256(24)$ & $1437(29)$ \\
\hline
\end{tabular}

†Includes 40 patients known to have been tested for HIV where information on requesting and/or offering tests was unknown.

${ }^{\star}$ Other includes contacts of those with STIs, sexual assault, needlestick, and other exposures to blood, IVF screening, those not sexually active, non-acute STIs. 
diagnosed in the year up to 31 July 1998 had not been given their HIV test result by the time of the survey in October 1998. This was out of approximately 1000 patients diagnosed in these clinics during this time period.

Current guidelines from the General Medical Council advise that pretest discussion is necessary before performing an HIV test except in exceptional circumstances. ${ }^{8}$ The large majority of consultants surveyed concurred with these guidelines and about a quarter favoured testing for HIV with assumed consent after it had been mentioned as one of a number of routine tests.

Consultants' estimates of their own rates of HIV testing were found often to be higher than the true rate of testing in the clinics as a whole. A substantial minority (39\%) of consultants responding thought that the proportion of attenders tested for HIV at their clinic was too low. Half of the reasons given for this low rate of testing were barriers dependent on the patient (table 2). The other half of the reasons given concerned barriers dependent on the clinic. The issue of resources was prominent.

The retrospective case note survey covered nearly 5000 patients in 53 clinics. Whereas the majority of those at high risk of HIV requested a test, this was not true of heterosexuals who had lived in sub-Saharan Africa. This category includes those born in sub-Saharan Africa, who accounted for $46 \%$ of HIV-1 infected heterosexuals attending genitourinary medicine clinics in a recent survey. ${ }^{9}$ Our finding of a low uptake of the HIV test among those from subSaharan Africa is pertinent to the earlier report that, compared with other groups, Africans with HIV present with more advanced disease.$^{10}$ Concerns about confidentiality are extremely common among this group. ${ }^{11}$ Different beliefs about health and the use of modern medicine may also be significant factors. ${ }^{11} \mathrm{~A}$ greater understanding of these differences may contribute to encouraging higher levels of testing while avoiding the stigmatising of this population. There is a need for further work in this area.

According to the Anonymous HIV Seroprevalence Monitoring Programme, HIV positive known injecting drug users attending clinics are very likely to have their infection diagnosed ( 22 of $25,88 \%$ ).

In conclusion, although the United Kingdom has a relatively low prevalence of HIV infection compared to much of Europe, there are no grounds for complacency. Most HIV infections in the United Kingdom are diagnosed in genitourinary medicine clinics, but still a substantial minority of people with HIV infection attending these clinics fail to have their HIV diagnosed. This study has shown that among attenders at high risk of HIV who did not request a test, a substantial minority $(29 \%)$ were not offered one by clinic staff.

Among lead clinicians who felt that HIV testing in their clinics was too low, the most frequently cited reason was a lack of resources. These findings have implications for clinic HIV testing policies, and resource allocation in genitourinary medicine departments in the United Kingdom.

We would like to thank the lead clinicians and other clinic staff who participated in these surveys.

\section{British Co-operative Clinical Group}

WRITING COMMITTEE

Chris Carne, consultant in genitourinary medicine, Addenbrooke's Hospital, Cambridge

Neil Macdonald, senior scientist, PHLS Communicable Disease Surveillance Centre

Colindale, London

Graz Luzzi, consultant in genitourinary medicine, Wycombe Hospital, High Wycombe

Adam Lawrence, consultant in genitourinary medicine, Victoria Sexual Health Clinic, Westminster, London

Noel Gill, consultant epidemiologist, PHLS Communicable Disease Surveillance Centre, Colindale, London

DATA COLLECTION AND ENTRY

Angela McHenry, senior scientist, PHLS Communicable Diseases Surveillance Centre, Colindale, London

PARTICIPATING MEMBERS OF BRITISH CO-OPERATIVE CLINICAL GROUP (BCCG)

GR Kinghorn (Chairman), CA Carne (Secretary), AB Alawattegama, C Bignell, GA Luzzi, P Kell, D Mandal, A McMillan, RD Maw, J Meaden, AT Nayagam, RS Pattman, K Radcliffe, A de Ruiter, J Scott, C Skinner, O Williams, FE Willmott, J Wilson.

1 Department of Health. Prevalence of HIV in England and Wales in 1997. Annual report of the unlinked anonymous prevalence monitoring programme. London: $\mathrm{DoH}, 1998$.

2 Changes in the incidence of AIDS and in AIDS deaths: the effects of anti-retroviral treatment. Commun Dis Rep CDR Wkly 1997;43:381.

3 Gazzard B, Moyle G. 1998 Revision to the British HIV Association guidelines for antiretroviral treatment of HIV seropositive individuals. Lancet 1998;352:314-16.

4 Fox R, Odaka NJ, Brookmeyer R, et al. Effect of HIV antibody disclosure on subsequent sexual activity in homosexual men. AIDS 1987;1:241-6.

5 AIDS and HIV infection in the United Kingdom: monthly report. Commun Dis Rep CDR Wkly 1998;8:9.

report. Commun Dis Rep CDR W Kly 1998;8:9.
6 AIDS and HIV infection in the United Kingdom: monthly AIDS and HIV infection in the United Kingdom: m
report. Common Dis Rep CDR Wkly 1999;9:277-80.

7 report. Common Dis Rep CDR Wkly 1999;9:277-80. CDC. HIV counselling and testing in publicly funded sites: 1995
summary report. Atlanta: US Department of Health and summary report. Atlanta: US Depa
Human Services, September 1997.

8 Serious communicable diseases. London: General Medical Serious communicab

9 McGarrigle CA, Nicoll A. Prevalence of HIV-1 among attenders at sexually transmitted disease clinics: analyses according to country of birth. Sex Transm Inf 1998;74:41520

10 Del Amo J, Petruckevitch A, Phillips AN, et al. Spectrum of diseases in Africans with AIDS. AIDS 1996;10:1563-9.

11 McMunn AM, Mwanje R, Pozniak AL. Issues facing Africans in London with HIV infection. Genitourin Med 1997;73:157-8 